\title{
Effect of the Microalloying Elements on Nucleation and Growth Kinetics of Allotriomorphic Ferrite in Medium Carbon-Manganese Steels
}

\author{
C. García de Andrés ${ }^{1}$, C. Capdevila ${ }^{1}$ and F.G. Caballero ${ }^{1,2}$ \\ ${ }^{1}$ Department of Physical Metallurgy, Centro Nacional de Investigaciones Metalúrgicas (CENiM), \\ Consejo Superior de Investigaciones Científicas (CSIC), \\ Avda. Gregorio del Amo 8, E-28040 Madrid, Spain \\ 2 Department of Materials Science and Metallurgy, University of Cambridge, \\ Pembroke Street, Cambridge CB2 3QZ UK
}

Keywords: Microalloyed Steels, Allotriomorphic Ferrite, Nucleation, Growth Kinetic

\begin{abstract}
The influence of alloying elements on nucleation and growth kinetics of allotriomorphic ferrite has been studied using dilatometric techniques and microstructural analysis in four medium carbonmanganese steels $(0.3 \% \mathrm{C}-1.4 \% \mathrm{Mn})$. A careful comparison between a $\mathrm{C}-\mathrm{Mn}$ steel and microalloyed steels containing $\mathrm{V}, \mathrm{Ti}$ and $\mathrm{Mo}$ subjected to isothermal transformation confirmed that all these elements delay the allotriomorphic ferrite transformation. More significant effect has been found by adding Mo, compared with the effect of the $\mathrm{V}$ and $\mathrm{Ti}$.
\end{abstract}

\section{INTRODUCTION}

Titanium and vanadium microalloyed steels are used extensively in forged automotive components [1-2]. Titanium is added with the aim of refining the microstructure through the inhibiting effect to grain coarsening exerted by small TiN precipitates [3-5]. Vanadium is selected due to its precipitation hardening capability, with a view to improve the toughness properties [6-8]. It has been found that toughness and strength can be improved simultaneously by transforming the austenite mainly in a fine acicular microstructure [9-12]. Consequently, there has been considerable effort towards maximizing the amount of acicular ferrite in the final microstructure.

Several authors showed that the presence of a uniform layer of allotriomorphic ferrite along the austenite grain surface induces the transformation of austenite in acicular ferrite instead of bainite [13-15]. In this sense, allotriomorphic ferrite formation plays a particular and important role in influencing the development of acicular ferrite in mixed microstructures.

The purpose of the present study is to clarify experimentally the influence of $\mathrm{Ti}, \mathrm{V}$ and $\mathrm{V}$ - Ti additions on the allotriomorphic ferrite transformation and indirectly, on the development of the intragranular transformation of acicular ferrite in microalloyed forging steels. The effect of molybdenum on the allotriomorphic ferrite transformation in a V-Ti microalloyed steel has also been studied.

\section{MATERIALS AND EXPERIMENTAL PROCEDURE}

Four medium carbon manganese steels were used in the present study and their chemical compositions are shown in Table 1 . Carbon $(\approx 0.3 \%)$ and manganese $(\approx 1.4 \%)$ contents are similar in 
all the steels. Three of them are microalloyed steels with different vanadium and titanium contents. In addition, V-Ti-Mo steel contains $0.12 \%$ Mo

Table 1. Chemical compositions (mass \%).

\begin{tabular}{lccccccccccc}
\hline \multicolumn{1}{c}{ Steel } & $\mathrm{C}$ & $\mathrm{Mn}$ & $\mathrm{Cu}$ & $\mathrm{Cr}$ & $\mathrm{S}$ & $\mathrm{Si}$ & $\mathrm{Al}$ & $\mathrm{Ni}$ & $\mathrm{V}$ & $\mathrm{Ti}$ & $\mathrm{Mo}$ \\
\hline $\mathrm{C}-\mathrm{Mn}$ & 0.31 & 1.22 & - & - & 0.011 & 0.25 & - & 0.10 & 0.004 & - & 0.03 \\
V & 0.33 & 1.49 & 0.27 & 0.13 & 0.002 & 0.25 & 0.027 & 0.11 & 0.240 & 0.002 & 0.04 \\
V-Ti & 0.32 & 1.39 & 0.13 & 0.13 & 0.021 & 0.33 & 0.027 & 0.14 & 0.130 & 0.039 & 0.03 \\
V-Ti-Mo & 0.30 & 1.51 & 0.20 & 0.25 & 0.030 & 0.32 & 0.020 & 0.14 & 0.110 & 0.020 & 0.12 \\
\hline
\end{tabular}

An Adamel Lhomargy DT1000 high resolution dilatometer has been used to determine the nucleation curves corresponding to the isothermal transformation of austenite of these steels. The dimensional variations of the specimen are transmitted via an amorphous silica pushrod. These variations are measured by an LVDT sensor in a gas-tight enclosure enabling testing under vacuum or in an inert atmosphere. The heating and cooling devices of this dilatometer were also used to perform all heat treatments. The DT 1000 dilatometer is equipped with a radiation furnace for heating. The power radiated by two tungsten filament lamps is focussed on a specimen of small dimensions ( $2 \mathrm{~mm}$ thickness and $12 \mathrm{~mm}$ length) by means of a bi-elliptical reflector. The temperature is measured with a $0.1 \mathrm{~mm}$ diameter Chromel-Alumel (Type $\mathrm{K}$ ) thermocouple welded to the specimen. Cooling is carried out by blowing a jet of helium gas directly onto the specimen surface. The helium flow rate during cooling is controlled by a proportional servovalve. The excellent efficiency of heat transmission and the very low thermal inertia of the system ensure that the heating and cooling rates ranging from $0.003 \mathrm{~K} / \mathrm{s}$ to approximately $200 \mathrm{~K} / \mathrm{s}$ remain constant.

Dilatometer specimens were austenitized and subsequently isothermally transformed at temperatures in the range of 873 to $973 \mathrm{~K}$ at different times. After isothermal transformation, specimens were gasquenched. They were polished and etched in the usual way. The allotriomorphic ferrite volume fraction $(v f A F)$ was estimated from optical micrographs by an unbiased systematic manual point counting procedure based upon stereological principles [16].

\section{RESULTS AND DISCUSSION}

As it is well known, prior austenite grain size (PAGS) exerts an important influence on the decomposition of austenite [17-18]. The PAGS parameter affects directly the allotriomorphic ferrite growth kinetic obtained by isothermal decomposition of the austenite. Nevertheless, there is no influence on the nucleation time of this phase [19-21].

Austenitization conditions were selected to achieve the same PAGS in all the steels, thus avoiding the influence of the austenite grain size on the allotriomorphic ferrite formation. This enables us to study specifically the effect of the microalloying elements on the growth kinetics of this phase. Since the growth rate of allotriomorphs is higher in finer $P A G S$, a coarse $P A G S$ of $70 \mu \mathrm{m}$ approx. was selected in order to facilitate the study of the growth kinetic of allotriomorphic ferrite. Austenitization conditions and the achieved PAGS are shown in Table 2 
Table 2. Austenitization conditions.

\begin{tabular}{cccc}
\hline Steel & Austenitization Temperature, $\mathrm{K}$ & Holding Time, $\mathrm{s}$ & PA(GS, $\mu \mathrm{m}$ \\
\hline C-Mn & 1473 & 120 & 70 \\
V & 1473 & 300 & 75 \\
V-Ti & 1523 & 180 & 72 \\
V-Ti-Mo & 1473 & 120 & 75 \\
\hline
\end{tabular}

Effect of microalloying elements on the nucleation time is given in Fig. 1. It can be seen that C-Mn steel presents the shortest time for the nucleation of the allotriomorphs. All the microalloying elements delayed the nucleation of this phase. Comparison of the nucleation curves of $\mathrm{V}$ steel $(0.24 \% \mathrm{~V}, 0.002 \% \mathrm{Ti})$ and $\mathrm{V}-\mathrm{Ti}$ steel $(0.13 \% \mathrm{~V}, 0.039 \% \mathrm{Ti})$ suggests that the effect of vanadium on the nucleation time is more important than the one of titanium. Moreover, V-Ti-Mo steel presents the longest nucleation time. Bearing in mind the titanium and molybdenum contents of $\mathrm{V}$ - $\mathrm{Ti}$ steel $(0.039 \% \mathrm{Ti}, 0.03 \% \mathrm{Mo})$ and $\mathrm{V}$-Ti-Mo steel $(0.020 \% \mathrm{Ti}, 0.12 \% \mathrm{Mo})$, it can be concluded that molybdenum exerts a strong influence on the nucleation of the allotriomorphic ferrite. The time needed for the nucleation of ferrite in $\mathrm{V}-\mathrm{Ti}-\mathrm{Mo}$ steel is longer than the one in $\mathrm{V}-\mathrm{Ti}$ steel, though the titanium content in the first steel is lower.

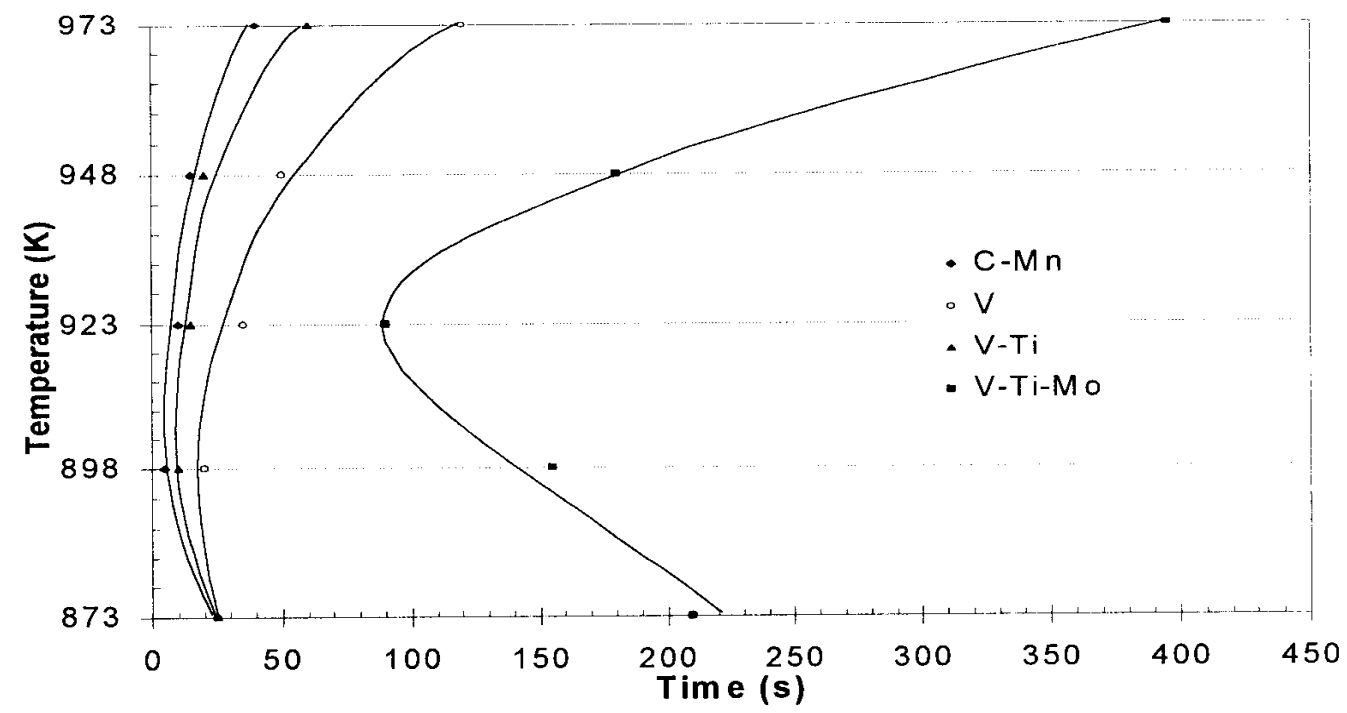

Figure 1. Nucleation of allotriomorphic ferrite.

The temperatures $\left(T_{i}\right)$, at which the incubation time of allotriomorphic ferrite $\left(t_{i}\right)$ is minimum, are reported in Table 3 . This temperature is approximately the same in $\mathrm{C}-\mathrm{Mn}, \mathrm{V}$ and $\mathrm{V}-\mathrm{Ti}$ steels. In this sense, vanadium and titanium do not seem to exert any influence on this temperature $T_{i}$. However, the molybdenum content in $\mathrm{V}$-Ti-Mo steel raises $T_{i}$ temperature at $923 \mathrm{~K}$, which is consistent with the work of Kinsman and Aaronson [22]. 
Table 3. Temperature and time of the nose of nucleation curves.

\begin{tabular}{lcc}
\hline Steel & Isothermal Temperature $T_{i,}, \mathbf{K}$ & Nucleation Time $t_{i}, \mathbf{S}$ \\
\hline C-Mn & 898 & 5 \\
V & 898 & 10 \\
V-Ti & 898 & 20 \\
V-Ti-Mo & 923 & 90 \\
\hline
\end{tabular}

With the aim of studying the growth kinetic of allotriomorphic ferrite at the same conditions in all the steels, this work has been carried out at the temperatures $T_{i}$ reported in Table 3. Experimental kinetic results for the growth of allotriomorphic ferrite at $T_{i}$ temperature are shown in Fig. 2 for the four steels. In this figure, the incubation time $\left(t_{i}\right)$ of every steel is taken as origin of time. The growth curves of Fig. 2 are plotted exclusively in the range of times for which the allotriomorphic ferrite is the only transformation that takes place. In C-Mn steel, Widmanstätten ferrite appears a few seconds after allotriomorphic ferrite is nucleated. However, in order to evaluate the effect of the microalloying elements on the growth kinetic of allotriomorphic ferrite, the curve of this steel has been plotted for the times below $15 \mathrm{~s}$, at which pearlite starts forming and a volume fraction of Widmanstätten ferrite lower than $2 \%$ is detected. Widmanstätten ferrite has been found in none of the microalloyed steels at their corresponding temperatures $T_{i}$. Table 4 reports the time required to nucleate pearlite in all the steels, taking as origin the corresponding incubation time $t_{i}$ for allotriomorphic ferrite.

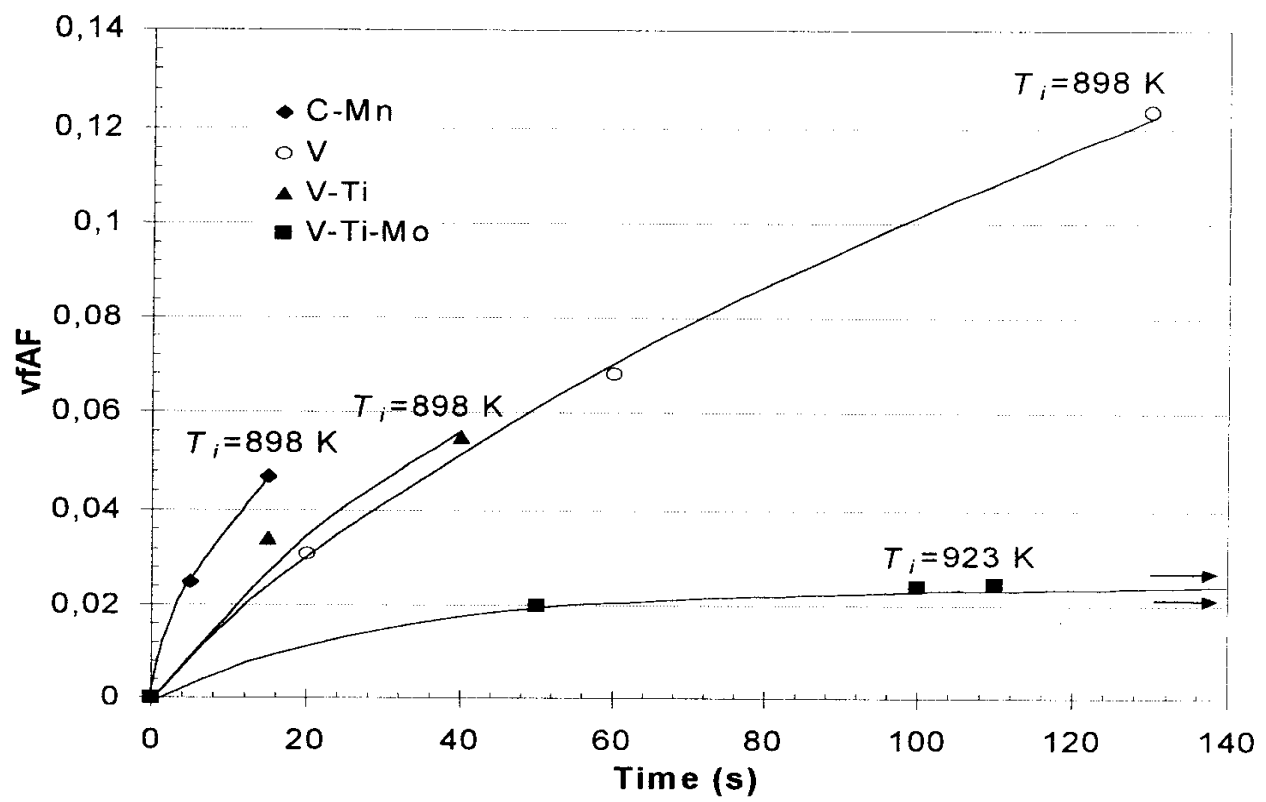

Figure 2. Growth kinetic of allotriomorphic ferrite. 
Table 4. Nucleation time of pearlite.

\begin{tabular}{cc}
\hline Steel & Nucleation Time, s \\
\hline C-Mn & 15 \\
V & 40 \\
V-Ti & 130 \\
V-Ti-Mo & $>900$ \\
\hline
\end{tabular}

The influence of the microalloying elements on the growth rate of allotriomorphic ferrite is clear from the isothermal kinetic results shown in Fig. 2. Vanadium decreases the growth rate of ferrite more severely than the titanium does. As in nucleation, molybdenum exerts an important influence on the kinetic growth of ferrite. The growth rate in V-Ti-Mo steel is significantly slower than in the other three steels. Moreover, molybdenum is responsible for the delay in the formation of pearlite. The nucleation time of this phase is found to be much longer in this steel (Table 4). Vanadium also seems to have a certain influence on the nucleation of pearlite.

\section{CONCLUSIONS}

1. Vanadium and titanium delay the nucleation of allotriomorphic ferrite in $0.3 \mathrm{C}-1.4 \mathrm{Mn}$ steels. The effect of vanadium in the nucleation of ferrite is more important than the one of titanium. Experimental results show that the addition of $0.12 \%$ Mo in a microalloyed steel containing vanadium and titanium significantly retards the nucleation of allotriomorphic ferrite.

2. Molybdenum raises the temperature at which the incubation time of allotriomorphic ferrite is minimum. Microallying elements such as vanadium and titanium do not seem to exert any influence on this temperature.

3. Formation of Widmanstätten ferrite is inhibited by the microalloying elements considered in this work, whereas an significant volume fraction of this phase has been found in C-Mn steel.

4. Vanadium decreases the growth rate of allotriomorphic ferrite more severely than the titanium does. However, molybdenum combined with vanadium and titanium is the element that exerts the most significant influence on the growth rate of this phase.

\section{ACKNOWLEDGEMENTS}

The authors acknowledge financial support from the CICYT- Spain (project PETRI 95-0089-OP)

\section{REFERENCES}

[1] F. Peñalba, C. García de Andrés, M. Carsí and F. Zapirain, ISIJ Int. 32 (1992), p. 232

[2] F.B. Pickering, 'Physical Metallurgy and the Design of Steels', Applied Science Publishers, London (1978), p. I

[3] M.A. Linaza, J.L. Romero, J.M. Rodriguez-Ibabe and J.J. Urcola, Scripta Metallurgica et Materialia 29 (1993), p. 1217.

[4] B. Yunguang, G. Qiang and Z. Lianwei, 'HSLA Steels'95'. Proceedings of the 3rd international conference of HSLA steels held at Beijing, China, organised by The Chinese 
Society for Metals on 25-29 October 1995, China Society and Technology Press (1995), p. 259.

[5] P.A. Manohar, D.P. Dunne, T. Chandra and R. Killmore, ISIJ Int. 36 (1996), p. 194.

[6] M. Zhang and D.V. Edmonds, 'HSLA Steels'95'. Proceedings of the 3rd international conference of HSLA steels held at Beijing, China, organised by The Chinese Society for Metals on 25-29 October 1995, China Society and Technology Press (1995), p. 133.

[7] F. Peñalba, C. García de Andrés, M. Carsi and F. Zapirain, Journal of Materials Science 31 (1996), p. 3847.

[8] J.L. Romero, 'Mejora de las Propiedades Mecanicas en Aceros en Contenido Medio en Carbono Microaleados con $\mathrm{Ti}$ y/o V para Forja y Laminacion, mediante Tratamientos Termomecanicos', PhD Thesis, Universidad of Navarra (1996), p. 71.

[9] R.E. Dolby, 'Factors Controlling Weld Toughness-The Present Position, Part II-Weld Metals', Welding Institute Research Report, No. 14/1976/M,Welding Institute, London (1976), p. 75.

[10] H.K.D.H Bhadeshia, 'Mathematical Modelling of Weld Phenomena', Materials Modelling Series, Institute of Materials, Edited by H. Cerjak, London (1995), p. 71.

[11] M.A. Linaza, J.L. Romero, I. San Martin, J.M. Rodriguez-Ibabe and J.J. Urcola, 'Microalloyed Bar and Forging Steels', Edited by C.J. Van Tyne, G. Krauss and D.K. Matlock, The Minerals, Metals and Materials Society (1996), p. 311

[12] M.A. Linaza, J.L. Romero, I. San Martin, J.M. Rodriguez-Ibabe and J.J. Urcola, Scripta Metallurgica et Materialia 29 (1993), p. 1217.

[13] H.K.D.H. Bhadeshia, 'Bainite in Steels', The Institute of Metals, London (1992), p. 174.

[14] H.K.D.H. Bhadeshia and S.S. Babu, Materials Transactions JIM 32 (1991), p. 679.

[15] H.K.D.H. Bhadeshia and S.S. Babu, Materials Science and Technology 6 (1990), p. 1005.

[16] G.F. Vander Voort, 'Metallography. Principles and Practice', McGraw-Hill Book Company, New York (1984), p. 427

[17] J. Bardford and W.S. Owen, J. Iron Steel Institute 197 (1961), p. 146.

[18] A.K. Sinha, 'Ferrous Physical Metallurgy', Butterworths, Boston, USA (1989), p. 379.

[19] K.C. Russell, Acta Metall. 16 (1968), p. 761.

[20] K.C. Russell, Acta Metall. 17 (1969), p. 1123.

[21] H.K.D.H Bhadeshia, Metal Sci. 16 (1982), p. 159.

[22] K.R Kinsman and H.I Aaronson, 'Transformations and Hardenability in Steels', Climax Molybdenum Co., Ann Arbor, Michigan (1967), p. 39.

Dr. C. García de Andrés

E-mail address: cgda@cenim.csic.es

Fax number: 07-34-1-5347425 